\title{
A Study on Lateral Stability of Articulated Heavy Vehicles with Central Axle Trailers
}

\author{
Qinghui Zhou ${ }^{1}$, Long Xiao' ${ }^{1}$ Y Yuping $\mathrm{He}^{2 *}$ \\ ${ }^{1}$ School of Mechanical-Electrical and Vehicle Engineering, Beijing University of Civil Engineering and Architecture, Beijing, \\ China \\ ${ }^{2}$ Department of Automotive, Mechanical and Manufacturing Engineering, Ontario Technology University, Oshawa, Canada \\ *e-mail:Yuping.He@uoit.ca
}

\begin{abstract}
Recently, articulated heavy vehicles (AHVs) with central axle trailers have been widely used in China, especially since issuing the national standard, GB1589-2016. However, traffic accidents involved AHVs with central axle trailers occur frequently. In order to address the problem and improve the stability of AHVs with central axle trailers, this paper generates a 3 degrees of freedom (DOF) yaw-plane AHV model, and analyses its dynamic responses under a simulated evasive maneuver. The influences of different trailer parameters on the AHV high-speed stability are examined. It shows that the dominant parameters affected the stability are trailer axle positions related to its center of gravity (CG), and other trailer geometric parameters. Trailer axle position poses the most important influence on the stability.
\end{abstract}

Keywords-component; Lateral stability; Central Axle Trailers; Articulated Heavy Vehicles; Parametric Study; Dynamic Stability;

\section{INTRODUCTION}

After issuing the national standard, GB1589-2016, "Limits of dimensions, axle load and masses for motor vehicles, trailers and combination vehicles", central axle trailers are developed and produced in China. A central axle vehicle combination consists of a towing unit and a trailer, as shown in Fig 1. The trailer, whose axle is positioned at its center, is a full trailer. Since its load is located at the CG of the trailer, only a small vertical load is applied to the towing unit when the vehicle is operating.

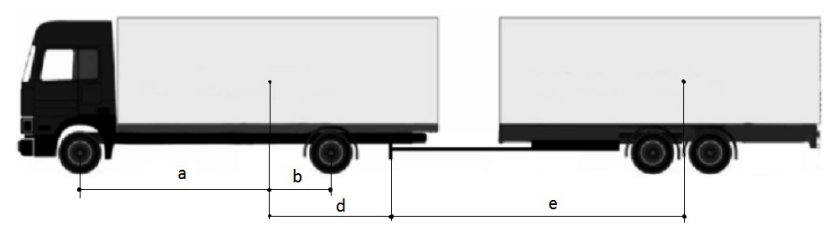

Fig 1: Side view for the AHV with a central axle trailer

The central axle trailer is connected with the tractor by a connecting device, also named a coupler, a kind of master and slave hook. In the case of a semi-trailer, the semi-trailer connects to the tractor by a fifth-wheel, and the trailer's tandem or trident axle group is located near the rear end of the trailer. Therefore, compared with the typical tractor/semitrailer combination, the AHV with a central axle trailer may exhibit a poorer stability. In order to reduce the risk of sway or swing and improve the stability of central axle trailer, numerical simulation based on a 3-DOF yaw-plane AHV model is conducted.

Some studies have examined the effects of parameters variations on the stability of central axle trailer in recent years. Yang et al. conducted a performance optimization for a centre axle trailer combination [1]. Zhang et al. studied handling stability and parameter optimization of centre axle trailer train [2]. Huang et al. established the dynamic model of a centre axle trailer train and optimized the parameters of the centre axle trailer train [3]. More elaborate mathematical models are used to evaluate various vehicle design configurations. As for various types of trailers and/or semi-trailers, Barbieri et al. conducted a study to compare the differences in dynamic behavior and the resulting stability of the different configurations under different conditions of speed and maneuvers [4]. Law and Janajreh developed a simplified computational tool that can be used to understand and predict the effects of various tire characteristics and truck design parameters on rollover under steady cornering and non-tripped conditions [5]. An analysis approach was proposed to assess tractor/trailer performance due to wind speed and wind gusts on slippery surfaces [6].

Because the lateral stability of AHVs cannot be guaranteed in varied operating conditions, a dynamic response to a steering input under a simulated single lane-change was examined to enhance the the stability of AHVs with a central axle trailer. The parameter sensitivity analysis was conducted using numerical simulation, which can be used for the stability prediction of AHVs.

\section{VEHICLE SYSTEM MODEL}

In order to evaluate the performance of an AHV, the model with 3 DOF, representing the AHV with a central axle trailer, is generated. Fig 2 shows the 3-DOF yaw-plane AHV model. 


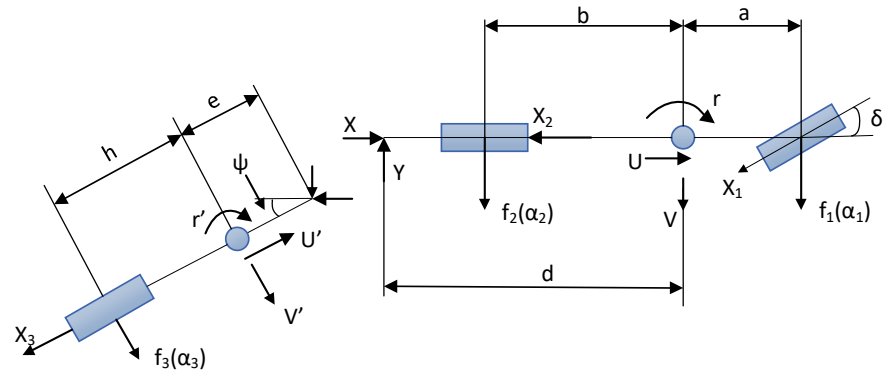

Fig 2: 3-DOF yaw-plane AHV model

The equations of the motions of the towing vehicle unit can be expressed as follows:

$$
\begin{aligned}
& m_{1}(\dot{U}-V r)=-X_{1} \cos \delta-X_{2}+X \\
& m_{1}(\dot{V}+U r)=f_{1}\left(\alpha_{1}\right)+f_{2}\left(\alpha_{2}\right)+X_{1} \sin \delta-Y \\
& I_{1} \dot{r}=\alpha f_{1}\left(\alpha_{1}\right)-b f_{2}\left(\alpha_{2}\right)+a X_{1} \sin \delta+d Y
\end{aligned}
$$

The equations of the motions of the central axle trailer are written as:

$$
\begin{aligned}
& m_{2}\left(\dot{U}^{\prime}-V^{\prime} r^{\prime}\right)=-X_{3}-Y \sin \psi-X \cos \psi \\
& m_{2}\left(\dot{V}^{\prime}+U^{\prime} r^{\prime}\right)=f_{3}\left(\alpha_{3}\right)+Y \cos \psi-X \sin \psi \\
& I_{2} \dot{r}^{\prime}=h f_{3}\left(\alpha_{3}\right)-e(-Y \cos \psi+X \sin \psi)
\end{aligned}
$$

The towing and trailing units are connected at the articulation joint. The velocities and accelerations at the point expressed in the coordinate systems fixed with the tractor or trailer must be equal. This allows the trailer equations to be written in the tractor fixed coordination system. Based on the following assumptions, the equations are linearized:

1) The forward speed $U$ is a constant and the forward motion equations (1) and (4) are ignored

2) Small angle approximations are used:

$$
\cos \psi=1, \sin \psi=\psi
$$

3) All products of variables are ignored.

4) Linear tire model is used.

For zero initial conditions:

$$
\dot{\psi}=r-r^{\prime}
$$

The linearized equations of motion can be written in the statespace form as

$$
M\{\dot{x}\}+D\{x\}+F \delta=0
$$

where

$$
\{x\}=\{V, r, \dot{\psi}, \psi\}
$$

The matrices M, D, and F, are provided in the Appendix. Table 1 lists the vehicle parameters and nominal values. Notation for vehicle variables and parameters is provided in Table 2.

Table 1: Vehicle system parameters and their nominal values

\begin{tabular}{|c|c|c|}
\hline Description & Notation & Value \\
\hline Tractor mass $(\mathrm{Kg})$ & $\mathrm{m}_{1}$ & 7850 \\
\hline Tractor yaw inertia $\left(\mathrm{Kg} \cdot \mathrm{m}^{2}\right)$ & $\mathrm{I}_{1}$ & 50960 \\
\hline Tractor dimension $(\mathrm{m})$ & $\mathrm{a}$ & 2 \\
\hline Tractor dimension $(\mathrm{m})$ & $\mathrm{b}$ & 3.6 \\
\hline Tractor dimension $(\mathrm{m})$ & $\mathrm{d}$ & 5.25 \\
\hline Trailer mass $(\mathrm{Kg})$ & $\mathrm{m}_{2}$ & 5300 \\
\hline Trailer yaw inertia $\left(\mathrm{Kg} \cdot \mathrm{m}^{2}\right)$ & $\mathrm{I}_{2}$ & 29767.9 \\
\hline Trailer dimension $(\mathrm{m})$ & $\mathrm{e}$ & 6.11 \\
\hline Trailer dimension $(\mathrm{m})$ & $\mathrm{h}$ & 0 \\
\hline Front tire cornering stiffness $(\mathrm{N} / \mathrm{rad})$ & $\mathrm{c}_{1}$ & -113450 \\
\hline Rear tire cornering stiffness $(\mathrm{N} / \mathrm{rad})$ & $\mathrm{c}_{2}$ & -113450 \\
\hline Trailer tire cornering stiffness $(\mathrm{N} / \mathrm{rad})$ & $\mathrm{c}_{3}$ & -113450 \\
\hline
\end{tabular}

Table 2: Notation for vehicle variables and parameters

\begin{tabular}{|c|c|c|}
\hline Notation & Description & Unit \\
\hline $\mathrm{M}$ & Body mass & $\mathrm{Kg}$ \\
\hline $\mathrm{U}$ & Longitudinal velocity & $\mathrm{m} / \mathrm{s}$ \\
\hline $\mathrm{V}$ & Lateral velocity & $\mathrm{m} / \mathrm{s}$ \\
\hline $\mathrm{U}^{\prime}$ & Longitudinal velocity of trailer & $\mathrm{m} / \mathrm{s}$ \\
\hline $\mathrm{V}^{\prime}$ & Yateral velocity of trailer & $\mathrm{m} / \mathrm{s}$ \\
\hline$\gamma$ & Yaw rate of tractor trailer & $\mathrm{rad}$ \\
\hline$\gamma^{\prime}$ & Yaw moment of inertia & $\mathrm{rad}$ \\
\hline $\mathrm{I}$ & Distance from front axle to mass center & $\mathrm{Kg} \cdot \mathrm{m}^{2}$ \\
\hline $\mathrm{a}$ & Distance from rear axle to mass center & $\mathrm{m}$ \\
\hline $\mathrm{b}$ & Distance from mass center to articulated point & $\mathrm{m}$ \\
\hline $\mathrm{d}$ & Distance from trailer mass center to articulated point & $\mathrm{m}$ \\
\hline $\mathrm{e}$ & Distance from trailer mass center to trailer axle & $\mathrm{m}$ \\
\hline $\mathrm{h}$ & Articulation angle between tractor and trailer & $\mathrm{rad}$ \\
\hline$\psi$ & Tractor's front axle steering angle & $\mathrm{rad}$ \\
\hline$\delta$ & Longitudinal force & $\mathrm{N}$ \\
\hline $\mathrm{X}, \mathrm{X}_{1}, \mathrm{X}_{2}, \mathrm{X}_{3}$ & Lateral force & $\mathrm{N}$ \\
\hline $\mathrm{Y}, \mathrm{Y}_{1}, \mathrm{Y}_{2}, \mathrm{Y}_{3}$ & Tire cornering stiffness & $\mathrm{N} / \mathrm{rad}$ \\
\hline $\mathrm{c}$ & &
\end{tabular}

\section{DYNAMIC RESPONSES TO A STEERING INPUT}

\section{A. Test procedure}

The effects of geometric parameters of central axle trailer are examined through evaluating the vehicle dynamic responses to a simulated steering input. As shown in Fig 3, the steering input takes the form of one cycle of a sinusoidal wave, having a period of 3.14 seconds and a magnitude of 1 degree (0.0175 radians). By setting the initial values of all the state variables to 0 , it is assumed that the AHV is travelling along a straight line before the vehicle swerving. The maximum overshoot and the settling time are the primary performance measures used to evaluate the dynamic responses. 


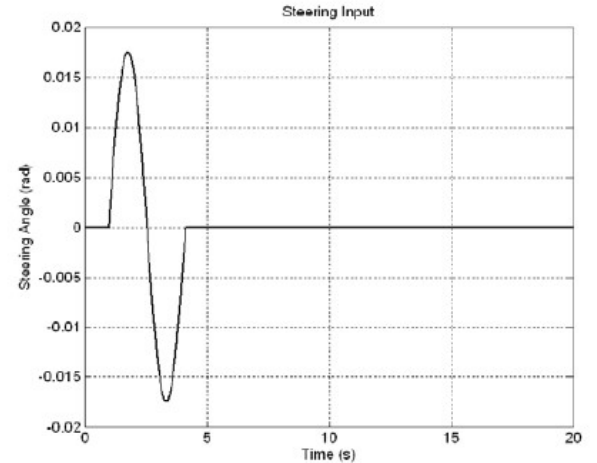

Fig 3: Simulated steering input

\section{B. Dynamic responses}

For vehicle combinations with centre-axle trailers, there may be a risk for instability due to lower yaw damping than semi-trailers. Fig 4 shows the dynamics responses of baseline vehicle at different forward speeds: $15 \mathrm{~m} / \mathrm{s}$ and $25 \mathrm{~m} / \mathrm{s}$, respectively. For the baseline vehicle, the magnitude of the tractor's dynamic responses, such as tractor lateral speed, yaw rate, and articulation angle, increase with time at the speed of $25 \mathrm{~m} / \mathrm{s}$ and the vehicle will lose stability. In contrast, for the same vehicle, the magnitude of the tractor's dynamics responses decrease with time at the speed of $15 \mathrm{~m} / \mathrm{s}$ and the vehicle is stable. The baseline vehicle's simulation results make sense since the vehicle's critical speed is $20 \mathrm{~m} / \mathrm{s}$, above which the vehicle will lose stability.

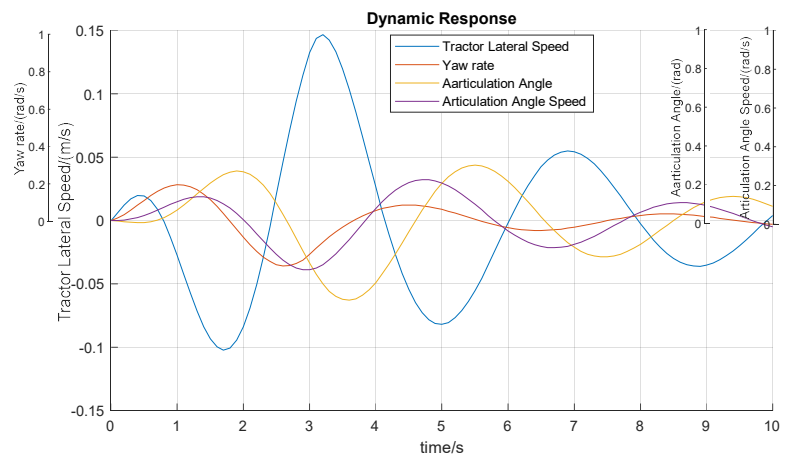

dynamic response at $15 \mathrm{~m} / \mathrm{s}$

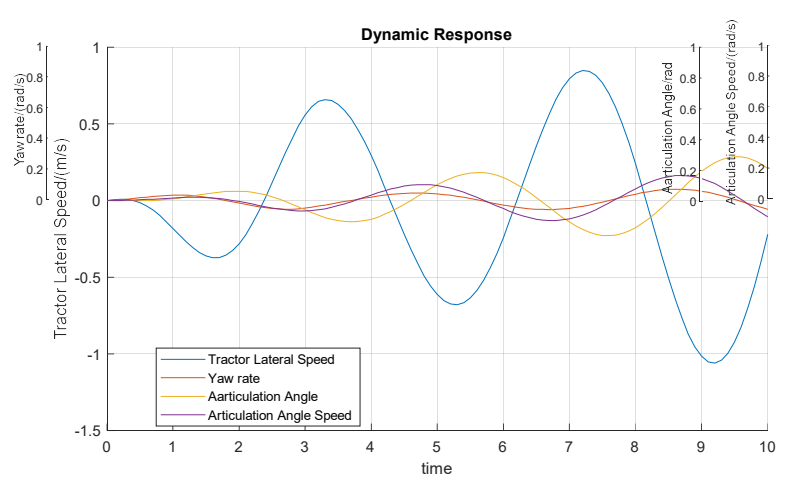

dynamic response at $25 \mathrm{~m} / \mathrm{s}$

Fig 4: Dynamic responses at different forward speed

\section{Results based on simulated single lane-change maneuver}

The single lane-change was used to establish the transient dynamic behavior of an AHV during an obstacle avoidance maneuver. Path deviation and trailer motion settling distances were measured with a goal of characterizing the amplification of the trailer motion for each unit in the vehicle. Of interest is the relative position (to tractor) of the trailer, along with yaw rate and lateral acceleration.

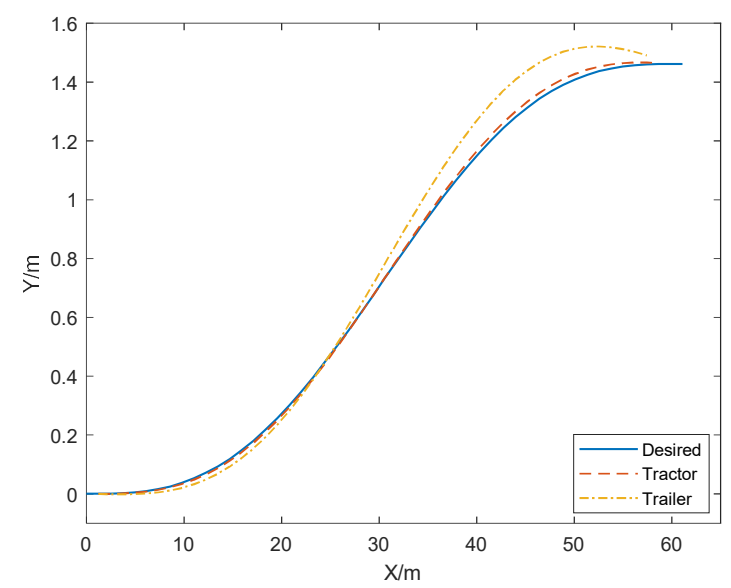

Fig 5: Single lane-change

According to ISO14791, the driver was instructed to drive the vehicle following the predefined track at $88 \mathrm{~km} / \mathrm{h}$. The driver was to move $1.46 \mathrm{~m}$ to the left lane while attempting to maintain a constant speed during the maneuver. The achieved simulation result in terms of high-speed off-tracking of the central axle trailer is shown in Fig 5. The path for the single lane-change begins with a straight segment to allow unwanted starting transients to settle, and then the vehicle moves to the left. The maximum offtracking of the central axle trailer is 0.50 $\mathrm{m}$.

\section{EFFECTS OF PARAMETERS ON LATERAL STABILITY}

As experimental study has been conducted to examine the efforts of important trailer parameters on the dynamic stability of a CT combination. The testing procedure and data processing approach were based on the corresponding methods specified by ISO-9815. To carry out a parametric study, one parameter was varied at a time, and the sample results are shown in Table 3 [9].

Table 3: Optimized geometric variables (permitted to vary by $\pm 2 \%$ from their nominal values)

\begin{tabular}{cccccc}
\hline Variables & $\begin{array}{c}\text { Nominal } \\
\text { values }\end{array}$ & $\begin{array}{c}\text { Optimized } \\
\text { values }\end{array}$ & $\begin{array}{c}\text { Nominal } \\
\mathrm{U}_{1 \mathrm{c}}\left(\mathrm{ms}^{-1}\right)\end{array}$ & $\begin{array}{c}\text { Optimized } \\
\mathrm{U}_{\mathrm{lc}}\left(\mathrm{ms}^{-1}\right)\end{array}$ & $\begin{array}{c}\text { Increase of } \\
\mathrm{U}_{\mathrm{lc}}(\%)\end{array}$ \\
\hline $\mathrm{a}(\mathrm{m})$ & 2 & $2.04 \uparrow$ & 20.451 & 20.456 & 0.024 \\
$\mathrm{~b}(\mathrm{~m})$ & 3.6 & $3.67 \uparrow$ & 20.451 & 20.681 & 1.124 \\
$\mathrm{~d}(\mathrm{~m})$ & 5.25 & $5.15 \downarrow$ & 20.451 & 20.672 & 1.081 \\
$\mathrm{e}(\mathrm{m})$ & 6.11 & $6.23 \uparrow$ & 20.451 & 20.910 & 2.244 \\
$\mathrm{~h}(\mathrm{~m})$ & 0 & $0.2 \uparrow$ & 20.451 & 24.450 & 19.554 \\
\hline
\end{tabular}

As shown in Table 3, with the given range of variation of the distance, optimizing $\mathrm{h}$ alone leads to a $19.55 \%$ increase in critical speed (U1c). Therefore, optimizing $h$ alone leads to approximately $81.36 \%$ contribution to the critical speed increase, resulting from the optimization of 
the geometric variable set (a combination of variables $a, b, d$, $\mathrm{e}$, and $\mathrm{h}$ ).

\section{CONCLUSIONS}

Stability is the most important parts of the performance of AHVs with a central axle trailer. The stability of an AHV with a central axle trailer was analyzed and evaluated, it was found that the dominant factor affecting stability is $h$, the distance between trailer CG and trailer axle. The trailer's center of gravity location relative to its resultant axle load location is a critical factor affecting the trailer stability. Thus, it is suggested that the CG of the trailer should be located in the front of trailer axle to improve the stability of central axle trailer. Except for $h$, other parameters, such as a, b, d and e also have important influence on the stability. The parameters are in order of e, b, d and a according to importance to the stability.

\section{REFERENCES}

[1] Yuliang Yang, Yu Yang, Ying Sun, et al., "Performance Optimization for the Centre Axle Trailer Combination”, SAE Int. J. Commer. Veh. 10(1), pp236-243, 2017

[2] Zhang Jingming, Ren Zekai, Zhang Hao, et al., "Handling stability and paremeter optimization of centre axle trailer train". Jouranl of tranffic and transportation engineering, Vol.18, pp:72-75, 1018

[3] Hang Zhichao, "Research of hangding stability and optimization of the center axle trailer train", Research institute of highway ministry of transport, 2018

[4] Barbieri, F., Lima, V., Garbin, L., and Boaretto, J., "Rollover Study of a Heavy Truck Combination with Two Different Semi-Trailer Suspension Configurations," SAE Technical Paper 2014-36-0025, 2014

[5] Law, E. and Janajreh, I., "Effects of Tire and Vehicle Design Characteristics on Rollover of Tractor Semi-Trailers," SAE Technical Paper 2004-01-1739, 2004
[6] Tremblay, J., Ziernicki, R., Railsback, B., and Kittel, M., "Wind Effects on Dynamic Stability of Tractor Trailers in Winter Conditions," SAE Technical Paper 2009-01-2915, 2009.

[7] I. S. Jacobs and C. P. Bean, "Fine particles, thin films and exchange anisotropy," in Magnetism, vol. III, G. T. Rado and H. Suhl, Eds. New York: Academic, 1963, pp. 271-350.

[8] Hac, A., Fulk, D., and Chen, H., "Stability and Control Considerations of Vehicle-Trailer Combination," SAE Int. J. Passeng. Cars - Mech. Syst 1(1):925-937, 2009

[9] Y. He, H. Elmaraghy, W. Elemaraghy (2005A), A design analysis approach for improving the stability of dynamic systems with application to the design of car-trailer systems, Journal of Vibration and control vol.11, No.12, pp.1487-1509

\section{APPENDIX}

$M=\left[\begin{array}{cccc}m_{1}+m_{2} & -m_{2} d & -m_{2} e & 0 \\ -m_{2} d & I_{1}+m_{2} d^{2} & m_{2} e d & 0 \\ -m_{2} e & m_{2} e d & I_{2}+m_{2} e^{2} & 0 \\ 0 & 0 & 0 & 1\end{array}\right]$

$D=\frac{1}{u} \backslash\left[\begin{array}{cccc}-c_{1}-c_{2}-c_{3} & -c_{1} a+c_{2} b+c_{3} d+\left(m_{1}+m_{2}\right) u^{2} & c_{3}(h+e) & -c_{3} u \\ -c_{1} a+c_{2} b+c_{3} d & -c_{1} a^{2}-c_{2} b^{2}-c_{3} d^{2}-m_{2} d u^{2} & -c_{3} d(h+e) & c_{3} d u \\ c_{3}(h+e) & -c_{3} d(h+e)-m_{2} e u^{2} & -c_{3}(h+e)^{2} & c_{3}(h+e) u \\ 0 & -u & u & 0\end{array}\right]$

$F=\left[\begin{array}{c}c_{1} \\ c_{1} a \\ 0 \\ 0\end{array}\right]$ 